\title{
Sentidos identitários de programação em TVs on-line ${ }^{1}$
}

Suzana Kilpp

\section{Resumo}

0 artigo é um relato parcial e resumido da fase três da pesquisa Audiovisualidades de web TVs, com o objetivo de autenticar os sentidos enunciados para a ethicidade programação em TVs on-line. Utilizamos a metodologia das molduras, com ênfase na dissecação das interfaces gráficas de duas plataformas de emissoras de TV e duas de web TVs na internet. 0s resultados obtidos apontam que tanto nas emissoras de TV quanto nas web TVs a programação on-line é outra coisa, para o que se precisa de outros conceitos e referências.

\section{Palavras-Chave}

Programação. TV on-line. Ethicidade, construto ou artefato. Moldura, molduração e emolduramento.
Suzana Kilpp I sukilp@unisinos.br Possui registro de socióloga, mestrado em História pela Pontifícia Universidade Católica do Rio Grande do Sul - PUCRS, Brasil. É doutora em Ciências da Comunicação pela Universidade do Vale do Rio dos Sinos - UNISINOS, Brasil. Atualmente, é professora do PPG em Ciências da Comunicação da UNISINOS e pesquisadora do CNPq (PQ 2).

\section{Introdução}

Há pouco mais de dez anos, afirmávamos que os sentidos identitários das coisas na coisa TV são ofertados em um compósito de quadros de experiência e significação que chamamos de molduras, sendo que chamamos as coisas de ethicidades: construtos televisivos das coisas com tal ou qual sentido imaginário (emolduramento). $\mathrm{Na}$ época, autenticamos as molduras e as ethicidades mais sólidas dessa construção, dentre as quais nos pareceu que a programação (em fluxo) era dentre elas a mais sólida, porque a mais duradoura. Em pesquisas subsequentes, afirmamos, a partir disso, que a imagem-duração (relacionada à programação em fluxo) seria justamente aquela que definiria a mídia televisão. E seguimos nossas pesquisas, usando sempre a metodologia das molduras, expandindo o corpus (sempre relacionado à TV).

Mais recentemente, problematizamos o que acontece quando as emissoras de TV passam a transmitir também on-line, e quando, na internet, começam a aparecer coisas chamadas de web TVs: nesses 
construtos, há ainda televisão (como a definíamos até então), e programação, e imagem-duração?

No sítio das emissoras off-line na internet, encontram-se basicamente imagens de arquivo dos programas, e, eventualmente, imagens de arquivo de vídeos relacionados feitos exclusivamente para exibição on-line. Parece que, para as emissoras, a internet tem sido até agora principalmente um sítio extensivo de sua programação off-line, no qual são arquivados materiais que podem ser acessados fora do fluxo, o que significa (em termos da maior interatividade ensejada pela digitalização) que os vídeos podem ser visualizados a qualquer momento, individualmente, por meio de catálogos ou menus (os quais não têm correspondência exata à grade de programação da emissora); e, diferentemente da TV off-line (em que é preciso aguardar o início de um programa), na TV on-line o usuário é quem decide ao que quer assistir e quando e em qual sequência (a não ser quando, também mais raramente, a emissora oferece assistir a uma transmissão simultânea²).

Já as web TVs não possuem outro sítio além do universo on-line. Se nelas também se encontram imagens de arquivo, de modo geral os vídeos estão organizados sob outro critério, porquanto, a princípio (frisamos!), não remetem a nada off- line. E enquanto uma TV on-line é uma extensão de apenas uma emissora, uma web TV é uma plataforma que agrega e organiza em catálogos ou menus vídeos ("programas") de "emissores" de diversos "canais", dentre os quais até pode haver ocasionalmente canais de emissoras de TV off-line: no mais das vezes, trata-se de um usuário que retransmite programas das emissoras (uma espécie de fake), e, quando isso ocorre, por ferir direitos autorais, a retransmissão e o canal são retirados do ar pelo administrador do site.

Ou seja, nas web TVs, basicamente, encontram-se, a princípio (novamente frisamos!), imagens de transmissões ditas ao vivo ou em tempo real de emissores detentores de canais da plataforma que não são (a princípio, mais uma vez!) detentores de canais de televisão. Nesses casos, os transmissores são pessoas (físicas ou jurídicas) quaisquer, e os receptores são usuários quaisquer que a assistem, e que ingerem sobre a transmissão enquanto a assistem no limite da usabilidade programada e nos termos protocolados por tal ou qual web TV.

\section{Ao considerar essas características, e em} conformidade com os objetivos da pesquisa, em sua fase três analisamos duas emissoras de TV (Globo e SBT) e duas web TVs (Justin TV e Ustream). A análise foi feita em duas etapas. Primeiro, ensaiamos diferentes formas de acesso de Brasília e na Universidade Católica de Brasília, em Brasília, de 09 a 12 de junho de 2015.

2 Mesmo que mais recentemente as emissoras transmitam simultaneamente parte de sua programação na internet, isso ocorre em uma janela-arquivo "ao vivo". 
à programação das web TVs (Justin TV e Ustream) a fim de verificar os percursos disponibilizados ao usuário para encontrar os "canais" que buscava, $\mathrm{e}$, neles, verificar: quais conteúdos eram transmitidos nas diferentes categorias organizadas no interior do canal; como eram transmitidos os conteúdos; e como podiam ocorrer as interações do usuário com o transmissor. Depois, acompanhamos as emissoras de TV (Globo e SBT) para verificar: 0 que havia de conteúdo exclusivo para a internet; 0 que havia de acervo da programação off-line; e quais os percursos sugeridos ao usuário para encontrar os vídeos que buscava.

Na sequência, apresentamos três conjuntos de apontamentos sobre o monitoramento realizado: no primeiro, tratamos das emissoras de TV; no segundo, das web TVs; no terceiro, comparamos as programações de Globo e SBT e de Justin TV e Ustream. ${ }^{3}$

\section{A programação das emissoras de TV}

Nesse caso, monitoramos os modos praticados pelas emissoras para anunciar, enunciar e veicular sua programação off-line na internet. No que segue, será facilmente percebido que não se tratava de simplesmente mudar de plataforma, pois a plataforma on-line requisitava, ela per se, ajustes no modus operandis das emissoras quanto a organizar e colecionar programas sob uma moldura genérica até então conhecida como programação e/ou grade de programação.

\subsection{Na TV Globo}

A grade de programação off-line da TV Globo podia ser encontrada no site oficial da Rede abaixo do logotipo da emissora, no link "Programação". Ao acessá-lo, o usuário era direcionado para 0 programa que estava no ar off-line. Na grade, ele aparecia destacado dos demais, e, no destaque, era possível obter informações sobre o horário de início e a caracterização do programa. Além disso, havia um link para 0 site do programa e botões (links) de compartilhamento nas redes sociais. 0s programas que já haviam sido exibidos apareciam sombreados, e os que ainda entrariam no ar apareciam coloridos.

A partir do site oficial de Rede Globo, também foi possível acessar as páginas de cada programa posicionando o cursor do mouse sobre a moldura "Programas". Nesse caso, as atrações apareciam organizadas em dez categorias (uma tipificação diferente da de gêneros5): "Vem Aí", "Novelas", "Variedades", "Esportes", "Infantil", "Séries", "Educação", "Auditório", "Humor" e "Jornalismo".

0 monitoramento e a dissecação do material empírico analisado neste artigo foram empreendidos, sob nossa orientação e supervisão, pela estudante de Jornalismo Fabricia Bogoni (PIBIC) e pela estudante de Comunicação Digital Juliana Gonçalves (BIC-FAPERGS), da UNISINOS.

Nesse texto, por conta da metodologia adotada, link sempre estará sendo entendido também como uma moldura praticada pela mídia; e também estará sendo entendido como uma ethicidade (um construto de link, perceptível no modo como se informa ao usuário uma conexão possível quando se passa o mouse sobre o termo ou figura). 
Nessa "grade", cada programa moldurado era um link. Ao clicar sobre um deles, 0 usuário era direcionado para o site específico do programa selecionado.

Na verdade, a Rede Globo se insere rizomaticamente em vários portais, o que permite que se navegue de um nó a outro do rizoma. Assim, por exemplo, ao clicar sobre a novela Malhação, podia-se ser remetido ao portal GShow; ao clicar sobre o noticiário Jornal Nacional, podia-se cair no portal G1; ao clicar sobre 0 programa Corujão do Esporte, podia-se chegar a ele no portal GloboEsporte.com.

Em todas as páginas de programas, havia uma moldura chamada "Vídeos". Essa ethicidade, por sua vez, era um catálogo, no qual cada itemmoldura era subdividido em novas categorias, sendo que a "grade" podia variar de acordo com a atração. Por exemplo: para Bem-Estar, existiam 32 subcategorias; para Pequenas Empresas, Grandes Negócios, apenas duas.

A moldura-ethicidade "Para Assinantes" aparecia em praticamente todos os catálogos, à exceção dos programas associados à "Globo Cidadania": Ação, Globo Ciência, Globo Ecologia, Globo Educação e Globo Universidade. 0 material disponível nesse trilho só podia ser visualizado integralmente por quem possuísse assinatura; ali, o conteúdo em vídeo se constituía de imagens do vídeo-programa integral sem cortes, enquanto que os vídeos das demais subcategorias eram fragmentos do original. No caso de "Globo Cidadania", nos catálogos havia sempre a opção de ver os programas na íntegra ou ver os blocos dos programas separadamente.

\subsection{No SBT}

No site oficial do SBT (http://www.sbt.com. br/home/), o usuário podia encontrar, logo no cabeçalho, a lista completa de programas off-line, o horário em que cada um era exibido diariamente, 0 acervo de vídeos-programas e as seções temáticas ("Jornalismo", "Filmes e Séries", "Notícias", "Jogos", "Promoções", "Inscrições" e "TV Local"). Nele, o usuário navegava em busca dos conteúdos da emissora, tanto do acervo da TV off-line quanto do exclusivo para a internet.

A grade de programação off-line de SBT podia ser encontrada em "Programação", link exposto no cabeçalho. Ao clicar sobre a palavra, a página atualizava uma barra horizontal dividida em dias da semana. As cores predominantes eram 0 amarelo e o vermelho-escuro. Automaticamente,

Aliás, na internet deu-se a ver ainda mais claramente o problema que relatamos em pesquisas anteriores quanto à complicada definição do gênero dos programas de TV, porquanto as emissoras confundem clássicas definições (que vêm da Literatura) com outras clássicas definições (que vêm das pesquisas de mercado sobre o público a que se destina o programa). Desde 2003, dissemos que tendemos a pensar que a TV engendra um "gênero televisivo", no qual as primeiras definições são subalternas às segundas definições, e resulta uma espécie peculiar de gênero best-seller, que poderia ser simploriamente definido a partir das respostas às seguintes questões: a) o que o mercado está "desejando" assistir nesse momento? b) como dar conta "desse desejo" em tal programa (a princípio, de tal gênero) no horário em que ele vai ao ar (a princípio, para tal público)?

Seções temáticas (frisamos), e não gêneros. 
o dia correspondente a acesso da grade ficava destacado na barra em vermelho-escuro. Abaixo da barra semanal, constava uma lista com os programas e os respectivos horários de exibição, sendo que os títulos eram antecedidos por "\#", um convite muito praticado na internet para compartilhamento nas redes sociais. ${ }^{7}$

Também nos programas, agrupados em categorias, a cor era 0 que diferenciava uma das outras: por exemplo, Casos de Família estava grifado em amarelo, a cor da categoria "Variedades"; e Café com Aroma de Mulher, em vermelho, a cor de "Novelas". Abaixo e acima, na lista, havia duas flechas que permitiam percorrer os horários da grade de programação, sendo que, quando se clicava em "Programação" o que estava no ar no momento do acesso ficava em destaque no topo da lista, com uma indicação em tarja vermelha "No Ar".

Exclusivamente para buscar 0 cardápio de filmes e séries, era possível acessar o link de mesmo nome disponível no cabeçalho. Na subcategoria "Filmes", chegava-se na "Central de Filmes", onde era possível ver o horário e onde se encaixava tal ou qual na programação; na subcategoria "Série" chegava-se a uma lista com todas as séries exibidas off-line na ocasião. As duas opções eram igualmente identificadas pela cor verde, tornandoas assim, enunciativamente, do mesmo gênero.
Por último, em vermelho, chegava-se na categoria "Especiais", com o índice de todos os programas desse gênero listados em ordem alfabética.

Também era possível chegar ao link "Confira a grade completa" da TV off-line na página inicial do site.

\subsubsection{Programas on-line}

Retomando: no site do SBT, "Programação" era um construto (uma ethicidade) que remetia o usuário ao conteúdo da TV off-line. E "Programas" era um construto (uma ethicidade) que 0 remetia à listagem completa de programas disponíveis online, dentre os quais os veiculados off-line.

Ainda que não ficasse imediatamente muito claro o que se encontrava em um sítio e noutro, via "Programas" chegava-se a seis categorias diferentes ou nomeadas de outro modo, novamente cada uma delas em uma cor identitária.

A primeira categoria recebia o nome de "Especiais", e também era de cor vermelha, como em "Programação" (relativa, lembramos, ao conteúdo off-line), e ali o usuário encontrava as seguintes opções: "0 melhor Comercial do Brasil", "SBT Folia", "SBT Na Web", "Sílvio Santos", "Teleton", "Troféu Imprensa", "Troféu Internet" e "Índice" (igual a "Todos os Sites"). "0 melhor 
Comercial do Brasil", "Troféu Imprensa" e "Troféu Internet" direcionavam o usuário para as páginas específicas das premiações. Como o próprio título da categoria explicava, tratava-se daqueles programas que são exibidos especialmente em certas ocasiões, no geral ocorrentes apenas uma vez ao ano, ou daqueles conteúdos especialmente reunidos sob a ethicidade programa para promover o SBT e/ou seu comandante. Assim, "SBT Folia" era a página da programação especial da emissora off-line durante os cinco dias de carnaval; "SBT na Web" (com conteúdo exclusivo para a TV on-line) mostrava os bastidores dos programas do SBT; "Sílvio Santos" era uma página especial criada para o dono da emissora, podendo estar ou não associada a veiculações off-line; "Teleton" era dedicado a vídeos relacionados à divulgação de ações de apoio do SBT à instituição AACD e às crianças carentes.

A segunda categoria, "Variedades", identificada pela cor laranja, reorganizava os programas offline de diferentes gêneros sob essa generalização, que abarcava nos extremos desde A Praça é Nossa até Gabi Quase Proibida, passando, por exemplo, por Máquina da Fama, Programa Sílvio Santos, Programa do Ratinho, Programa Raul Gil, Roda a Roda e Supernanny. Vários exibiam, além do conteúdo off-line, e conforme 0 formato do programa, conteúdos exclusivos para a internet: um breve resumo do programa e dos apresentadores, informações de como participar, notícias associadas, página para inscrições, fotos e quadros do programa etc., sendo que 0
Programa Sílvio Santos também oferecia "jogos" como conteúdo alternativo.

A terceira categoria, "Novelas", representada pela cor rosa, reunia sob esse gênero vários programas exibidos off-line pela emissora. Suas páginas eram semelhantes às dos programas da categoria "Variedades". Elas continham, além dos vídeos, informações sobre a novela e os personagens, fotos, horário de exibição e resumo dos capítulos. 0 layout do site seguia um padrão, com exceção de Rebelde e Carrossel. Mais uma vez a cor do link diferenciava uma novela da outra: 0 de $A$ Madrasta era bordô; o de Café com Aroma de Mulher, verde; 0 de $O$ Privilégio de Amar, roxo; o de Por Ela sou Eva, azul; e o de Por Teu Amor, vermelho. Na página de vídeo, havia 0 aviso de que os episódios permaneceriam on-line por apenas sete dias. Entretanto, alguns vídeos permaneciam por mais um tempo no site, às vezes, por um mês. A página da novela Rebelde ainda oferecia conexão com o Facebook para postagem e exibição de comentários dos usuários, conexão que também encontramos na página SBT na Web.

A quarta categoria, identificada pela cor verde, era "Filmes/Séries", oferecia três opções (subcategorias?) ao usuário: Patrulha Salvadora, Central de Filmes e Todas as Séries, sendo que a segunda e a terceira correspondiam a uma coleção, e a primeira era um destaque dentro da coleção "Séries". Ou seja, de fato, eram duas coleções: uma de filmes e outra de séries, sendo que uma das séries era tão destacada 
que, enunciativamente, ficava alçada a uma

"subcategoria" terceira, reforçando nosso entendimento de que as afinidades eletivas que constelam gêneros e programas na internet seguem outros parâmetros dos praticados pelas emissoras off-line, ainda mais aleatórios e imprecisos, especialmente se nos dois casos levarmos em conta os gêneros literários originais. Patrulha Salvadora era uma série infantil exibida pelo SBT. Sua página seguia o padrão do site no que diz respeito ao conteúdo. Já Central de Filmes era a página onde eram anunciados e disponibilizados os filmes exibidos off-line no decorrer de duas semanas: além dos vídeos, era possível obter informações como a classificação etária e o horário de exibição; ao clicar no link Saiba Mais, disponível logo abaixo de cada título, o usuário era direcionado para uma página com informações extras, como, por exemplo, sinopse, elenco e diretor, e com espaço para comentários. Ao clicar na última opção, Todas as Séries, 0 usuário era direcionado para a listagem de séries (uma subcategoria) disponíveis na categoria Filmes e Séries.

Na categoria "Infantil", identificada pela cor roxa, eram listados três programas voltados para crianças (Bom Dia \& Cia, Chaves e Sábado Animado), mais um quarto, Clubinho SBT, o qual remetia à outra página que reunia novamente $\mathrm{os}$ três programas citados e mais dois jogos para crianças. Por conta do público-alvo, o layout tinha uma aparência mais colorida, mas mantinha a cor verde como padrão do cabeçalho.
Já na última categoria, "Jornalismo", de cor azul, encontravam-se os quatro telejornais da emissora: Conexão Repórter, Jornal do SBT, SBT Brasil e SBT Manhã. Todas as páginas apresentavam resumo do programa e dos apresentadores, reportagens, notícias e vídeos das edições já transmitidas na TV. Ao mesmo tempo em que esse conteúdo encontra-se no menu Programas, ele aparecia no menu Programação também como "Jornalismo". Ao clicar nele, o usuário era direcionado para uma página na qual, novamente, se chegava aos telejornais da emissora, com 0 mesmo cabeçalho e o mesmo conteúdo. Além disso, na página inicial, os mesmos vídeos (e outros) eram disponibilizados nas categorias "SBT Brasil", "Estados Unidos", "Veja Também", "Mais Notícias", "Comportamento", "Brasília”, "Íntegra SBT Manhã", "Íntegra SBT Brasil" e "Íntegra Jornal do SBT".

\subsubsection{SBT Vídeos}

A maior parte do conteúdo on-line do SBT (e, estritamente, os vídeos, inclusive os que já haviam saído do ar) também podia ser acessada através do menu SBT Vídeos, no qual eram disponibilizados todos os vídeos da TV off-line e os com conteúdo exclusivo para a internet (SBT na Web). Para acessar o acervo, o usuário devia clicar em SBT Vídeos, o terceiro menu disponível no cabeçalho. Ao fazer isso, ele era direcionado para uma página exclusiva de vídeos, reunidos em uma extensa coleção que incluía vídeos institucionais, como os de campanhas, chamadas de programas e vinhetas especiais do canal. 
Esses vídeos também estavam organizados em categorias identificadas por cor, as mesmas usadas para as categorias acessadas em outros links. As únicas que não apareciam em Programas eram "TV Local" e "Institucional", de cor cinza e vermelha, respectivamente. Ao clicar em uma das categorias, o usuário via as opções de vídeos disponíveis, os quais também podiam ser acessados pelas subcategorias "Mais Assistidos", "Mais Recentes" e "TV Local". Assim como em outras práticas já destacadas, vê-se aí uma forte tendência da emissora adotar parâmetros de indexação praticados na internet em plataformas de compartilhamento de vídeos.

Uma segunda maneira de chegar a vídeos específicos era disponibilizada no lado direito do cabeçalho do acervo, em um campo aberto de "busca", em que 0 usuário devia digitar o nome do programa para, a partir dele, chegar ao vídeo buscado.

\section{A programação das web TVs}

Nesse caso, monitoramos os modos praticados por TVs originárias da internet, as que só existem on-line, para anunciar, enunciar e veicular sua programação. No que segue, será facilmente percebido que não se tratava de dar origem a um novo fenômeno, mas de reinventar a mídia TV, nos termos permitidos pela web, com vistas a resolver insuficiências apontadas (e duramente criticadas) da mídia tradicional (off-line). Nesse viés, autenticamos duas plataformas, bastante populares, nas quais foram feitos investimentos técnicos, estéticos e operacionais (principalmente) para produzir "essa diferença": a Justin TV e a Ustream.

Ambas permitiam ao usuário transmitir conteúdo ao vivo, assistir aos canais de outros transmissores e, ainda, interagir com outras pessoas enquanto ele acompanhava a transmissão. $\mathrm{Na}$ internet, mais especificamente nessas duas plataformas, 0 transmissor apenas precisava possuir uma conta para produzir e veicular a sua própria programação. Para utilizar os serviços de Justin TV, era preciso entrar no endereço eletrônico http://www.justin.tv e cadastrar-se (abrir uma conta e receber a concessão de um "canal"); para utilizar os serviços de Ustream, por sua vez, era preciso acessar http://www.ustream. tv e cadastrar-se (abrir uma conta e receber a concessão de um "canal").

\subsection{Na Justin TV}

Na página inicial de Justin TV, os canais eram ofertados em "Top Featured Channels" e "Trending Timelapse Vídeos". Na plataforma, o usuário também podia buscar canais no link "Explore" e na barra de categoria de canais.

Em "Top Featured Channels", o site mostrava alguns canais que transmitiam ao vivo, e os deixava em destaque. 0 primeiro canal da lista era sempre apresentado em um player de vídeo grande, o qual rodava automaticamente ao se acessar a página inicial de Justin TV. Os dez 
canais ofertados nesse espaço eram de categorias diversas e variavam a cada acesso. Em "Trending Timelapse Vídeos", o site apresentava nove vídeos de transmissões realizadas na categoria "Creativity". Geralmente, essas transmissões duravam horas, pois os transmissores eram artistas (da pintura, do desenho, da música, etc.) que costumavam mostrar o dia a dia de seu trabalho. No entanto, com a ferramenta Timelapse, após o fim de uma transmissão, era possível gerar vídeos com cerca de três a cinco minutos de duração, de forma a que os usuários pudessem assistir apenas a uma edição resumida do material bruto. Assim como em "Top Featured Channels", os vídeos desse espaço eram substituídos por outros frequentemente.

Em "Explore" - link localizado no topo da página de Justin TV, em uma barra de botões, ao lado do logotipo do site -, ao posicionar 0 cursor do mouse sobre 0 botão, abria-se um retângulo dividido em duas seções: "View live channels by category" e "Broadcast your video". Na primeira, o usuário encontrava a seguinte lista de categorias: "All Channels", "Featured", "Animals", "Creativity", "Entertainment", "News", "Poker", "Sports", "Social" e "Other". Em outro lugar da página inicial, abaixo do quadro de faixas informativas, a lado do número de canais ao vivo no momento, também havia uma barra com categorias de canais.

No total, a Justin TV oferecia ao usuário dez categorias de canais, as mesmas nos dois acessos citados. "All Channels" apresentava uma pequena mostra dos canais ao vivo no momento (no máximo, seis de cada categoria). "Featured" reunia canais em destaque na página inicial (mas também destacava outros canais, aleatoriamente). "Animals" reunia os canais ao vivo sobre animais. "Creativity" apresentava os canais ao vivo sobre animações, desenhos, trabalhos manuais e outros trabalhos criativos. "Entertainment" oferecia um cardápio de canais ao vivo sobre filmes, programas, séries de TV e desenhos animados. "News" oferecia uma coleção de canais ao vivo sobre programas de notícias. "Poker" reunia canais ao vivo sobre jogos de carta. "Sports" oferecia canais ao vivo sobre partidas de futebol e competições de outros esportes, assim como de programas esportivos. "Social" reunia canais ao vivo com conversas entre usuários, e alguns mostravam também um pouco sobre 0 cotidiano das pessoas. "Other", enfim, reunia os canais ao vivo que não se encaixavam nas demais categorias.

\subsection{Em Ustream}

Logo na página inicial dessa web TV, eram mostrados flashes dos "Featured shows": oito canais diferentes, em geral com transmissão ao vivo, transmitidos por usuários assinantes e que se encontravam em destaque no momento. Normalmente, esses vídeos contabilizavam um grande número de visualizações desde o momento em que começavam a ser exibidos. 0s números apresentados referiam os usuários que já haviam 
assistido ao vídeo e os usuários que 0 estavam assistindo no momento.

No cabeçalho do site, ao lado da logomarca da web TV, encontrava-se o link "Explorar". Ao passar o mouse sobre 0 termo, encontravam-se cinco categorias recomendadas ("Popular", "Upcoming", "Seguindo", "Recentemente Assistido" e "Amigos") e nove categorias gerais ("Notícias", "GamingPS4", "Entretenimento", "Esportes", "Animais", "Spirituality", "Tecnologia", "Educação" e "24/7"). Ao clicar em uma das categorias, o usuário era encaminhado para a página com aquele tipo específico de programa. Caso o usuário clicasse em "Explorar", ele era automaticamente direcionado para a categoria "Popular".

Em "Popular", eram exibidos os vídeos mais assistidos no momento, a maioria com transmissão ao vivo, independentemente do tipo de conteúdo, e os vídeos eram listados em ordem decrescente de viewers, não havendo prioridade de exibição para usuários assinantes. Em "Upcoming", eram anunciados os vídeos que ainda seriam disponibilizados, com informações adicionais (como data e horário) e a opção de pedir para ser lembrado quando sua veiculação estaria disponível. Em "Seguindo", os vídeos transmitidos por canais que o usuário segue eram mostrados com destaque na página; caso ele não estivesse seguindo nenhum, a página aparecia em branco. Em "Recentemente assistido", encontrávamos os vídeos recentemente vistos pelo usuário e que ainda permaneciam no histórico do site. Em "Amigos", era possível assistir aos vídeos também assistidos pelos amigos do usuário no Facebook.

Quanto às demais categorias (chamadas de gerais), nelas encontramos as seguintes molduras para os vídeos disponíveis: em "Notícias", eram exibidos telejornais, previsão do tempo e reportagens diversas; em "Gaming - PS4", eram oferecidos vídeos de jogos on-line sendo jogados ao vivo pelo dono do canal, e também vídeos de eventos da empresa Sony sobre Playstation 4 e um vídeo tutorial sobre o PS4; "Entretenimento" era uma coleção de canais de moda, notícias de famosos, conteúdo relacionado a filmes e séries e entretenimento em geral; "Esportes" oferecia vídeos de esportes diversos, desde bilhar até boxe e futebol americano, por exemplo; "Animais" reunia diferentes tipos de vídeo com foco em animais, geralmente gravados com câmeras fixas em um determinado cenário mostrando o dia a dia de um animal; "Spirituality" reunia vídeos de cultos religiosos, apresentações em igrejas e programas relacionados à religião; em "Tecnologia", encontramos canais com conteúdo "científico" com forte ênfase em TICs, como vídeos sobre a NASA, sobre robôs e informática em geral; em "Educação", a maioria dos vídeos relacionavase a how-to, tutoriais, palestras e seminários; a categoria "24/7" oferecia vídeos on-line 24 horas por dia, sete dias por semana, ou seja, destacava programações on-line full time.

Outra maneira de procurar o conteúdo desejado no acervo da plataforma era através da moldura 
"Search", disponível no cabeçalho do site. Em sua busca, a partir de qualquer termo, o usuário encontrava três filtros: categoria, quando o vídeo fora exibido e onde. E, se 0 usuário estivesse logado ao Facebook, ele era automaticamente conectado ao site da Ustream na rede social.

\section{Conclusões parciais a considerar}

A programação de TV (off-line) é pensada a partir de uma grade matricial que imagina e organiza os programas de um canal-emissora, a princípio por horário (que subentende um espectador de TV nesse horário) e gênero (o qual subentende 0 interesse do espectador desse horário).

No Brasil, os canais são, a princípio, do Estado, e as emissoras que veiculam sua programação através deles são apenas suas concessionárias. Também a princípio, a empresa que recebe a concessão deve ser avaliada de tempos em tempos quanto a estar atendendo ao princípio constitucional de que 0 serviço de comunicação em TV é público, podendo a concessão ser cassada se a empresa não estiver atendendo ao definido em lei. Na internet, poderia-se dizer que a concessão é, diferentemente, feita pela empresa que mantém a plataforma e oferece 0 serviço. Sua regulamentação nos é desconhecida, mas tendemos a pensar que nada tem a ver com qualquer coisa que se possa chamar de interesse público, ainda que o termo se preste, em um caso e em outro, a vários sentidos (e arbitragens, e por que não? - a vários arbítrios).

Na internet também se deu a ver mais claramente o problema que relatamos em pesquisas anteriores quanto à complicada definição do gênero dos programas de TV, porquanto as emissoras confundem clássicas definições (que vêm da Literatura ${ }^{8}$ ) com outras clássicas definições (que vêm das pesquisas de mercado sobre o público a que se destina o programa). Ainda tendemos a pensar que a TV off-line engendra um gênero televisivo, no qual as primeiras (definições) são subalternas às segundas, e resulta uma espécie peculiar de gênero best-seller, o qual poderia ser simploriamente definido a partir das respostas às seguintes questões: a) 0 que 0 mercado está desejando assistir nesse momento? b) como dar conta desse desejo em tal programa (a princípio, de tal gênero) no horário em que ele vai ao ar (a princípio, para tal público)? 0n-line, na internet, fica muito claro que são essas as questões que pautam a organização matricial (grade) do conteúdo programático, tanto nas TVs quanto nas web TVs.

Off-line, no entanto, a grade não se restringe, nem de longe, a um cardápio ou à montagem de um somatório de programas, pois se torna, no fluxo da emissão, uma macromontagem de unidades autônomas de conteúdo (dentre as 
quais, fragmentos de programas). No fluxo da nossa espectação, ocorre o mesmo, só que nossa macromontagem é definitivamente pessoal, ainda que seja atravessada por nossa participação e referência na tecnocultura: assistimos TV no tempo que dedicamos pessoalmente a isso (que, dificilmente, coincide com o horário da programação), zappeando, colando tempos de TV (e nossos) de um canal e de outro e de nossas próprias ocupações com um conjunto de coisas enquanto assistimos TV, etc.

Sob tais parâmetros e conforme a metodologia adotada - da qual também faz parte a intuição (nos termos de Bergson, apud Deleuze, 2004) e produzir constelações (nos termos de Benjamin, apud Didi-Huberman, 1998) -, cartografamos os modos de comparecimento da ethicidade programação nas interfaces gráficas do corpus da pesquisa e dissecamos as molduras praticadas em cada uma delas para lhe conferir sentidos identitários. Constelamos assim algumas imagens que são críticas, porque nelas coalescem passado (TV off-line) e presente (TV on-line). E porque ambas perduram, elas são também contemporâneas (nos termos de Agamben, 2009), e dizem algo sobre as imagens de nosso tempo.

\subsection{Imagens críticas nas constelações gênero e programa}

Nas grades da TV Globo e do SBT off-line (conforme veiculadas na internet), as faixas horárias eram preenchidas de forma semelhante, com dois gêneros prevalentes: "Jornalismo" e "Entretenimento". No segundo, os subgêneros eram diferentes de uma emissora e outra: resumidamente, em Globo, encontramos "Variedades", "Novelas", "Reality Shows", "Filmes" e "Séries"; em SBT, "Desenhos Animados", "Séries" e "Novelas". Em Globo, há um terceiro gênero prevalente: "Esportes". Já nas grades de Justin TV e Ustream, prevaleciam quatro seções temáticas: "Animais", "Entretenimento", "Notícias" e "Esportes". Ou seja, apenas a categoria "Animais" não teria correspondente na TV off-line, porquanto as demais, ainda que com outros nomes, se equivaleriam como gênero ou subgênero.

Entretanto, quando consideramos o teor veiculado em cada categoria cruzado com quem produziu cada conteúdo e como e quando foi veiculado, atravessou-se outro "gênero": 0 "ao vivo". 0 "ao vivo" nas TVs off-line situa-se, como gênero, em "reality shows", podendo ocorrer em "jornalismo" como modo de transmissão de acontecimentos jornalísticos em "tempo real". 0 "ao vivo" (ou em "tempo real") é, aliás, um dos maiores ruídos (a principal, talvez, imagem crítica da constelação) em todas as categorizações por gênero da programação de TV, desde a definição do que vem antes ou depois na generalização: 0 gênero (ainda literário) ou a midiatização da informação? 0 que é televisão: informação ou entretenimento? Imagem de arquivo ou narração do acontecimento?, etc. 
Em Justin TV e em Ustream, "Animais" era uma categoria que reunia os canais com transmissão ao vivo de jardins, pátios de casa, fazendas, sítios e demais localidades nos quais vivam bichos, domésticos ou não. 0 usuário assistia ao cotidiano full time desses animais sem interferência direta de pessoas durante a transmissão: a câmera que mostrava 0 ambiente era fixa e os animais se moviam em frente dela. A sensação era semelhante à de reality shows, e, embora se tratasse aparentemente de animais, no fundo, tratava-se das pessoas relacionadas a eles (outra imagem crítica).

Na internet, nas TVs off-line, "Jornalismo" englobava telejornais (de âmbito nacional e local), programas de jornalismo especializado e de jornalismo investigativo. 0 conteúdo disponibilizado on-line dessas atrações se constituía em reportagens na íntegra (Rede Globo) e em blocos na íntegra (SBT). Nas web TVs, os canais reunidos na categoria "Notícias" transmitiam telejornais da TV off-line de emissoras de várias partes do mundo em tempo real (mais uma imagem crítica).

\section{A categoria "Entretenimento" das web TVs} se assemelhava aos programas ofertados pela TV off-line sob esse gênero. Nas web TVs, também tínhamos "Novelas", "Séries", "Filmes", "Desenhos Animados". Novamente (como em "Notícias"), alguns programas da categoria eram retransmitidos de canais offline de referência, mas os usuários também transmitiam filmes e séries de TV aos quais possuíam acesso por outros meios que não os da TV on-line (mais uma imagem crítica).

A categoria "Esporte" das web TVs reunia canais que transmitiam programas esportivos do tipo mesa-redonda e jogos e competições de esportes como, por exemplo, futebol, futebol americano, vôlei, hóquei, motovelocidade, automobilismo e lutas. Mais uma vez (como em "Entretenimento" e em "Notícias"), as transmissões partiam do conteúdo exibido nesses termos por canais off-line (no caso, da TV Globo, pois o SBT não possuía programação esportiva enquanto gênero em sua programação, apenas noticiários esportivos e transmissões de competições ao vivo, como futebol, automobilismo e lutas).

Além disso, o teor dos programas exclusivamente on-line tinha algumas peculiaridades que merecem ser apontadas:

- no caso das emissoras de TV, nos vídeos prevalecia a mostragem de bastidores dos programas off-line e vídeos que remetiam 0 usuário à espectação off-line, uma espécie de imagem crítica às vinhetas e promos (os quais não eram praticados na internet);

- no caso das web TVs, nos vídeos prevalecia a mostragem de imagens feitas pelos usuários (especialmente sobre si, seu cotidiano e seus bastidores, narradas ou não por eles mesmos) ou feitas por outros (inclusive pelas emissoras de TV), uma 
imagem crítica do que a TV imagina ser o que o mercado (genericamente) está desejando assistir;

- nos vídeos das web TVs também prevaleciam narrações de si (diretas ou indiretas) do usuário em tempo real, uma imagem crítica dos reality shows e das narrações de si das emissoras de TV.

\subsection{Imagens críticas na constelação da grade matricial}

Não havia periodicidade fixa ou horário definido para as transmissões nos canais das web TVs, pois elas dependem da disponibilidade ou vontade do usuário.

Dentre as TVs off-line na internet, não era assim, mas não havia correspondência das transmissões com o que era praticado off-line. Por exemplo, episódios de programas semanais do SBT off-line eram disponibilizados semanalmente em seu canal no YouTube e também podiam ser visualizados no site oficial de SBT na internet. No caso da TV Globo, as séries eram disponibilizadas irregularmente, em horários alternativos, conforme o número de episódios da série, possivelmente porque isso incidia sobre a regularidade da grade. Por exemplo, os vários episódios semanais de $A$ Vida de Reinaldo Rangel foram postados na internet nas sextas-feiras durante a manhã; os apenas quatro episódios semanais de Histórias de Além do Horizonte e da Imaginação foram postados em quatro dias consecutivos da mesma semana. ${ }^{9}$

Ou seja, qualquer imagem da grade matricial offline na internet é uma imagem crítica.

\subsection{Imagens críticas na constelação fluxo}

Essas são, sem dúvida, as mais importantes imagens críticas que autenticamos na análise sobre a programação de TV quando ela se torna on-line, porquanto, na internet, tanto a oferta dos canais quanto a experiência do usuário jamais alcançam a ethicidade fluxo da programação televisiva. Sempre, mesmo quando o usuário consegue assistir à programação sob a moldura "ao vivo" ou sob a moldura "em tempo real" ou sob a moldura "transmissão simultânea", ele precisa agir (acionar vários botões e links) até chegar ao ponto da assistência inercial que lhe é oferecida naturalmente pela transmissão off-line. E apenas até que ele deseje "trocar de canal" (zappear), o que lhe demandará agir novamente (acionar vários botões e links), e agir, portanto, para além da ação que lhe é demandada pelo controle remoto da TV tradicional.

Esse talvez seja o preço a pagar pela interatividade (ainda bastante precária) autorizada pelos meios digitais, o preço a pagar 
para não ficarmos à mercê da TV: nunca mais

relaxaremos e gozaremos sentados no sofá

diante de um aparelho no qual desfilam imagens

quaisquer - desiguais e à nossa revelia - em fluxo

incessante como o fluxo incessante das imagens

do mundo da vida.

\section{Referências}

AGAMBEN, Giorgio. 0 que é o contemporâneo

e outros ensaios. Chapecó: Argos, 2009.

DELEUZE, Gilles. Bergsonismo. São Paulo:

Editora 34, 2004.

DIDI-HUBERMAN, Georges. 0 que vemos, o que

nos olha. São Paulo: Ed. 34, 1998.

KILPP, Suzana. Ethicidades Televisivas. Sentidos

identitários na televisão. São Leopoldo: Unisinos, 2003.

A traição das imagens. Porto Alegre:

Entremeios, 2010. 


\begin{tabular}{|c|c|}
\hline $\begin{array}{l}\text { What means programming } \\
\text { in on-line TVs }\end{array}$ & $\begin{array}{l}\text { Qué significa programación } \\
\text { en TVs online }\end{array}$ \\
\hline $\begin{array}{l}\text { Abstract } \\
\text { The article is a partial and summarized approach } \\
\text { of phase three of the research Audiovisualities of } \\
\text { web TVs with the objective to identify the directions } \\
\text { enunciated for programming in on-line TVs. We used } \\
\text { the frame methodology, with emphasis in analysis of } \\
\text { the graphical interfaces of two platforms of traditional } \\
\text { TVs in the internet and two platforms of web TVs. } \\
\text { The results suggest that the programming on-line } \\
\text { is another thing in both cases, and demands other } \\
\text { concepts and references to understanding it. } \\
\text { Keywords } \\
\text { Programming. On-line TV. Ethicity, frame and } \\
\text { do. Framing and meaning }\end{array}$ & $\begin{array}{l}\text { Resumen } \\
\text { El artículo es un resumen parcial de la fase tres de la } \\
\text { investigación "Audiovisualidades de web TVs", la qual } \\
\text { tenia como objectivo identificar los significados de } \\
\text { programs en TVs on-line. Utilizamos la metodología } \\
\text { de los enquadres, con énfasis en la disección de las } \\
\text { interfaces gráficas de dos estaciones de televisión } \\
\text { tradicionales, y la disección de las interfaces gráficas } \\
\text { de dos web TVs. Los resultados obtenidos muestran } \\
\text { que la programación es un fenomeno original cuando } \\
\text { se presenta online en las estaciones de TV y en las web } \\
\text { TVs, y que se necesita nuevos conceptos y referencias } \\
\text { para entender ese fenomeno. } \\
\text { Palabras clave } \\
\text { Programación. TV online. } \\
\text { Artefacto, encuadre y significación. }\end{array}$ \\
\hline
\end{tabular}




\section{Expediente}

A revista E-Compós é a publicação científica em formato eletrônico da Associação Nacional dos Programas de Pós-Graduação em Comunicação (Compós). Lançada em 2004, tem como principal finalidade difundir a produção acadêmica de pesquisadores da área de Comunicação, inseridos em instituições do Brasil e do exterior.

\section{E-COMPÓS I www.e-compos.org.br I E-ISSN 1808-2599}

Revista da Associação Nacional dos Programas de Pós-Graduação em Comunicação.

Brasília, v.18, n.3, set./dez. 2015.

A identificação das edições, a partir de 2008, passa a ser volume anual com três números.

Indexada por Latindex I www.latindex.unam.mx

\section{CONSELHO EDITORIAL}

Alexandre Farbiarz, Universidade Federal Fluminense, Brasil Alexandre Rocha da Silva, Universidade Federal do Rio Grande do Sul, Brasil Ana Carolina Damboriarena Escosteguy, Pontifícia Universidade Católica do Rio Grande do Sul, Brasil

Ana Carolina Rocha Pessôa Temer, Universidade Federal de Goiás, Brasil Ana Regina Barros Rego Leal, Universidade Federal do Piauí, Brasil Andrea França, Pontifícia Universidade Católica do Rio de Janeiro, Brasil André Luiz Martins Lemos, Universidade Federal da Bahia, Brasil Antonio Carlos Hohlfeldt, Pontifícia Universidade Católica do Rio Grande do Sul, Brasil

Arthur Ituassu, Pontifícia Universidade Católica do Rio de Janeiro, Brasil Álvaro Larangeira, Universidade Tuiuti do Paraná, Brasil Ângela Freire Prysthon, Universidade Federal de Pernambuco, Brasil César Geraldo Guimarães, Universidade Federal de Minas Gerais, Brasil Cláudio Novaes Pinto Coelho, Faculdade Cásper Líbero, Brasil Daisi Irmgard Vogel, Universidade Federal de Santa Catarina, Brasil Denize Correa Araujo, Universidade Tuiuti do Paraná, Brasil Eduardo Antonio de Jesus, Pontifícia Universidade Católica de Minas Gerais, Brasil

Daniela Zanetti, Universidade Federal do Espirito Santo, Brasil Eduardo Vicente, Universidade de São Paulo, Brasil Elizabeth Moraes Gonçalves, Universidade Metodista de São Paulo, Brasil Erick Felinto de Oliveira, Universidade do Estado do Rio de Janeiro, Brasil Francisco Elinaldo Teixeira, Universidade Estadual de Campinas, Brasil Francisco Paulo Jamil Almeida Marques, Universidade Federal do Paraná, Brasil

Gabriela Reinaldo, Universidade Federal do Ceará, Brasil Goiamérico Felício Carneiro Santos, Universidade Federal de Goiás, Brasil Gustavo Daudt Fischer, Universidade do Vale do Rio dos Sinos, Brasil Herom Vargas, Universidade Municipal de São Caetano do Sul, Brasil Itania Maria Mota Gomes, Universidade Federal da Bahia, Brasil
Janice Caiafa, Universidade Federal do Rio de Janeiro, Brasil Jiani Adriana Bonin, Universidade do Vale do Rio dos Sinos, Brasil José Afonso da Silva Junior, Universidade Federal de Pernambuco, Brasil José Luiz Aidar Prado, Pontifícia Universidade Católica de São Paulo, Brasil Juçara Gorski Brittes, Universidade Federal de Ouro Preto, Brasil Kati Caetano, Universidade Tuiuti do Paraná, Brasil

Lilian Cristina Monteiro França, Universidade Federal de Sergipe, Brasil Liziane Soares Guazina, Universidade de Brasília, Brasil Luíza Mônica Assis da Silva, Universidade de Caxias do Sul, Brasil Luciana Miranda Costa, Universidade Federal do Pará, Brasil Malena Segura Contrera, Universidade Paulista, Brasil Maria Ogécia Drigo, Universidade de Sorocaba, Brasil Maria Ataide Malcher, Universidade Federal do Pará, Brasil Marcia Tondato, Escola Superior de Propaganda e Marketing, Brasil Marcel Vieira Barreto Silva, Universidade Federal da Paraíba, Brasil Maria Clotilde Perez Rodrigues, Universidade de São Paulo, Brasil Maria das Graças Pinto Coelho, Universidade Federal do Rio Grande do Norte, Brasil

Mauricio Ribeiro da Silva, Universidade Paulista, Brasil

Mauro de Souza Ventura, Universidade Estadual Paulista, Brasil Márcio Souza Gonçalves, Universidade do Estado do Rio de Janeiro, Brasil Micael Maiolino Herschmann, Universidade Federal do Rio de Janeiro, Brasil Mirna Feitoza Pereira, Universidade Federal do Amazonas, Brasil Nísia Martins Rosario, Universidade Federal do Rio Grande do Sul, Brasil Potiguara Mendes Silveira Jr, Universidade Federal de Juiz de Fora, Brasil Regiane Regina Ribeiro, Universidade Federal do Paraná, Brasil Rogério Ferraraz, Universidade Anhembi Morumbi, Brasil Rose Melo Rocha, Escola Superior de Propaganda e Marketing, Brasil Rozinaldo Antonio Miani, Universidade Estadual de Londrina, Brasil Sérgio Luiz Gadini, Universidade Estadual de Ponta Grossa, Brasil Simone Maria Andrade Pereira de Sá, Universidade Federal Fluminense, Brasil Veneza Mayora Ronsini, Universidade Federal de Santa Maria, Brasil Walmir Albuquerque Barbosa, Universidade Federal do Amazonas, Brasil

\section{COMISSÃO EDITORIAL}

Cristiane Freitas Gutfreind

Pontifícia Universidade Católica do Rio Grande do Sul, Brasil

Irene Machado

Universidade de São Paulo, Brasil

\section{CONSULTORES AD HOC}

Claudia Peixoto de Moura, Pontificia Universidade Católica do Rio Grande do Sul, Brasil Francisco Rüdiger, Pontifícia Universidade Católica do Rio Grande do Sul, Brasil Juremir Machado da Silva, Pontifícia Universidade Católica do Rio Grande do Sul, Brasil Maria Aparecida Baccega, Universidade de São Paulo, Brasil

Roberto Tietzmann, Pontifícia Universidade Católica do Rio Grande do Sul, Brasil

\section{EQUIPE TÉCNICA}

ASSISTENTE EDITORIAL I Márcio Zanetti Negrini

REVISÃO DE TEXTOS I Press Revisão

EDITORAÇÃO ELETRÔNICA I Roka Estúdio

CONTATO I revistaecompos@gmail.com
COMPÓS I www.compos.org.br

Associação Nacional dos Programas de Pós-Graduação em Comunicação

Presidente

Edson Fernando Dalmonte

Programa de Pós-Graduação em Comunicação

e Cultura Contemporânea - UFBA

edsondalmonte@uol.com.br

Vice-presidente

Cristiane Freitas Gutfreind

Programa de Pós-Graduação em Comunicação Social - PUC-RS cristianefreitas@pucrs.br

Secretário-Geral

Rogério Ferraraz

Programa de Pós-Graduação em Comunicação

Universidade Anhembi Morumbi

rogerioferraraz@anhembimorumbi.edu.br 